\title{
Computer Aided Modeling and Analysis of Five-Phase PMBLDC Motor Drive for Low Power High Torque Application
}

\author{
M. A. Inayathullaah ${ }^{1}$ and R. Anita ${ }^{2}$ \\ ${ }^{1}$ Department of Electrical and Electronics Engineering, Periyar Maniammai University, Thanjavur District, Tamil Nadu 614201, India \\ ${ }^{2}$ Department of Electrical and Electronics Engineering, Institute of Road and Transport Technology, Erode District, \\ Tamil Nadu 638316, India
}

Correspondence should be addressed to M. A. Inayathullaah; mailtoinayath@yahoo.com

Received 24 April 2014; Accepted 25 June 2014; Published 23 July 2014

Academic Editor: Neil Y. Yen

Copyright (c) 2014 M. A. Inayathullaah and R. Anita. This is an open access article distributed under the Creative Commons Attribution License, which permits unrestricted use, distribution, and reproduction in any medium, provided the original work is properly cited.

\begin{abstract}
In order to achieve high torque at low power with high efficiency, a new five-phase permanent magnet brushless DC (PMBLDC) motor design was analyzed and optimized. A similar three-phase motor having the same $D / L$ ratio (inner diameter $(D)$ and length of the stator $(L)$ ) is compared for maximum torque and torque ripple of the designed five-phase PMBLDC motor. Maxwell software was used to build finite element simulation model of the motor. The internal complicated magnetic field distribution and dynamic performance simulation were obtained in different positions. No load and load characteristics of the five-phase PMBLDC motor were simulated, and the power consumption of materials was computed. The conformity of the final simulation results indicates that this method can be used to provide a theoretical basis for further optimal design of this new type of motor with its drive so as to improve the starting torque and reduce torque ripple of the motor.
\end{abstract}

\section{Introduction}

Brushless DC (BLDC) motor drives are stabbing the market in various consumer and industrial systems, such as home appliances, computer peripherals, automotive applications, and aerospace motor drives in recent years because of their high efficiency, silent operation, high reliability, and low maintenance requirement [1-3]. Power electronic converters are being utilized for variable speed drives. The power rating of the converter should meet the required level for the machine and driven load. However, the converter ratings cannot be increased over a certain range due to the limitation on the power rating of semiconductor devices.

The advent of inverter fed motor drives also removed the limits of the number of motor phases. This fact made it possible to design machine with more than three phases and brought about the increasing investigation and applications of five-phase motor drives. Five-phase motor drives have many advantages over the traditional three-phase motor drives such as reducing the amplitude and increasing the frequency of torque pulsation, reducing the stator current per phase without increasing the voltage per phase, and increasing the reliability and power density. The purpose of using such systems is mainly for achieving higher power level, reducing torque pulsation, increasing the torque density, and improving the reliability.

There are many performance analysis methods for the five-phase PMBLD motor such as direct circuit motor analysis, state equation simulation, analytic method of electromagnetic field, and electromagnetic finite element numerical method. In particular, finite element numerical analysis method is widely used in the analysis and calculation of various electrical equipment, and it can consider the circumstance of nonlinear ferromagnetic materials, as well as the changes of parameters in motor [4]. The electromagnetic analysis software of Maxwell was adopted to emulate the basic characteristics and the starting process of the five-phase PMBLD motor. The results show that this method is lucid and feasible. 


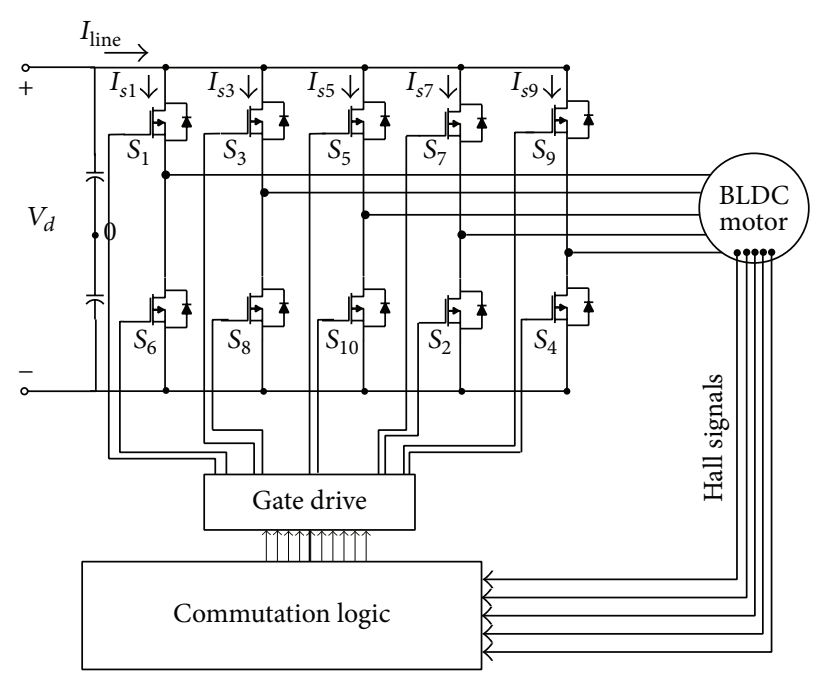

(a)

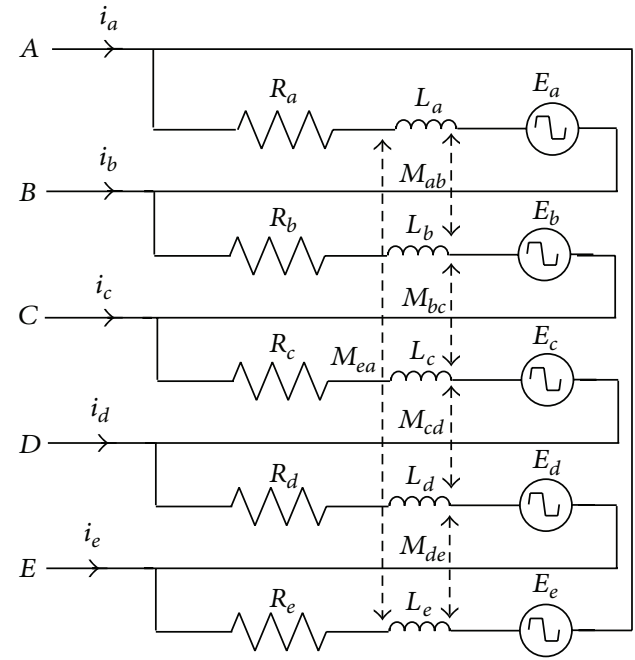

(b)

FIGURE 1: (a) Five-phase MOSFET inverter based BLDC motor drive; (b) equivalent electrical motor model.

\section{Mathematical Model of Five-Phase PMBLDC Motor}

The mathematical model of five-phase PMBLDC motor is given in [5]. Figures 1(a) and 1(b) show the overall system configuration of the five-phase BLDC motor drive and its equivalent electrical motor model. The PWM inverter topology is a ten-switch voltage source configuration with constant DC-link voltage $\left(V_{d}\right)$. The following assumption is made for simplification of the analysis to come.

(1) The motor is not saturated.

(2) Stator resistances of all the windings are equal, and self- and mutual inductances are constant.

(3) Power semiconductor devices in the inverter are ideal.

(4) Iron losses are negligible.

Among the above-mentioned assumptions, the iron loss can be approximated using empirical equations, and the dynamic characteristics of the switching devices need to be considered for the investigation of transient state behavior. Under the above assumptions, the five-phase PMBLDC motor can be represented as

$$
\left[\begin{array}{c}
V_{a b} \\
V_{b c} \\
V_{c d} \\
V_{d e} \\
V_{e a}
\end{array}\right]=R_{S}\left[\begin{array}{c}
i_{a}-i_{b} \\
i_{b}-i_{c} \\
i_{c}-i_{d} \\
i_{d}-i_{e} \\
i_{e}-i_{a}
\end{array}\right]+L_{S} \frac{d}{d t}\left[\begin{array}{l}
i_{a}-i_{b} \\
i_{b}-i_{c} \\
i_{c}-i_{d} \\
i_{d}-i_{e} \\
i_{e}-i_{a}
\end{array}\right]+\left[\begin{array}{c}
E_{a}-E_{b} \\
E_{b}-E_{c} \\
E_{c}-E_{d} \\
E_{d}-E_{e} \\
E_{e}-E_{a}
\end{array}\right],
$$

where $L_{a}, L_{b}, L_{c}, L_{d}, L_{e}=L$ are the self-inductance of each phase in Henry, $M_{a b}, M_{b c}, M_{c d}, M_{d e}, M_{e a}=M$ are the mutual inductances between the five phases in Henry, $L_{S}=L-M$ is the equivalent inductances per phase in Henry, $R_{a}, R_{b}, R_{c}, R_{d}$, $R_{e}=R$ are the per phase resistance of the five phases in Ohm,
$R_{S}=2 R$ is the effective line to line resistance in ohm, $V_{a b}, V_{b c}$, $V_{c d}, V_{d e}$, and $V_{e a}$ are the line to line voltages in volt, $i_{a}, i_{b}, i_{c}$, $i_{d}$, and $i_{e}$ are the phase currents of each coil in ampere, and $E_{a}, E_{b}, E_{c}, E_{d}$, and $E_{e}$ are trapezoidal back EMF in volt. The performance analysis of five-phase PMBLD motor is based on time domain mathematical model. Under these voltages, currents and total power loss of input power and output power are shown in (3)-(4). The output mechanical torque is shown as (6), and motor efficiency is shown as (7):

$$
\begin{gathered}
P_{\text {in }}=\frac{1}{T} \int_{0}^{T}\left(V_{a} i_{a}+V_{b} i_{b}+V_{c} i_{c}+V_{d} i_{d}+V_{e} i_{e}\right) d t \\
V_{a b}=V_{a} ; \quad V_{b c}=V_{b} ; \quad V_{c d}=V_{c} ; \\
V_{d e}=V_{d} ; \quad V_{e a}=V_{e}, \\
i_{a b}=\sqrt{1.38} i_{a} ; \quad i_{b c}=\sqrt{1.38} i_{b} ; \quad i_{c d}=\sqrt{1.38} i_{c} \\
i_{d e}=\sqrt{1.38} i_{d} ; \quad i_{e a}=\sqrt{1.38} i_{e} \\
P_{\text {out }}=P_{\text {in }}-P_{\text {loss }} \\
T_{\text {out }}=\frac{P_{\text {out }}}{\omega_{r}} \\
\eta_{t}=\frac{P_{\text {out }}}{P_{\text {in }}} * 100 \% .
\end{gathered}
$$

\section{Two-Dimensional Finite Element Model of Five-Phase PMBLDC Motor}

The model of five-phase PMBLDC motor was established and analyzed by Maxwell software. Initially, according to the requirement of the control system, the main technical parameters of the five-phase PMBLDC motor could be optimized, as given in Table 1. Then, two-dimensional finite 
TABLE 1: Geometric motor parameters.

\begin{tabular}{lc}
\hline Parameter & Value \\
\hline Rated voltage in volts & 24 \\
Rated speed in rpm & 3000 \\
Number of pole & 4 \\
Stator outer diameter in mm & 55.2 \\
Rotor outer diameter in mm & 45.6 \\
Rated power in watt & 210 \\
Number of phases & 5 \\
Slot number & 10 \\
Stator inner diameter in mm & 46.6 \\
Air gap in mm & 0.5 \\
\hline
\end{tabular}

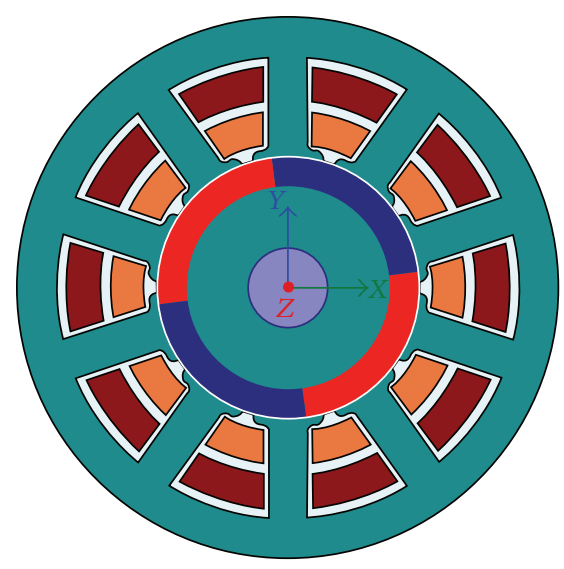

FIgURE 2: Two-dimensional finite element model (time: $0.02 \mathrm{~s}$ ).

element model was established by Maxwell 2D software, as shown in Figure 2. Finally, the no load and load of fivephase PMBLDC motor were computed and analyzed in the transient state module of Maxwell 2D.

3.1. Control Circuit System. To make an accurate simulation analysis, Maxwell circuit editor module in Ansoft software was adopted to establish the external circuit model and complete finite element model along with the geometric model that was established [6]. Control circuit system for driving the five-phase PMBLDC motor is mainly made up of the model of drive circuit and power converter. Control circuit system is shown in Figure 3. Here, V138 and V139 are voltage sources; D140 to D151, D169 to D172, and D175 to D178 are diodes; S_52 to S_57, S_67, S_68, S_73, and S_74 are voltage controlled switches; V120 to V125 and V218 to V221 are pulse voltage sources; IVC1 to IVC10 are ammeters; MOSFET power controllable switches and diodes were applied to simulate controllable switch silicon devices in the actual fivephase PMBLDC motor circuit. Diodes which are in series with the controllable switch are used to set the actual voltage drop. Besides, ten diodes are required as freewheeling diodes. Pulse voltage sources, ground voltage meters, and resistors are applied to the drive circuit model.

3.2. Finite Element Grid System. To ensure the accuracy of magnetic circuit calculation and magnetic field analysis, finite element grid was subdivided by manual mode. The magnetic field was divided into 22146 units by the methods of inside selection and surface approximation [7-9]. The overall subdivision model and the partial enlargement model are shown in Figures 4(a) and 4(b), respectively. The subdivision of finite element grid is relatively uniformly distributed on the whole, and the grid subdivision has a higher density in the field where the magnetic field is relatively strong and changes greatly, such as the air gap part. Therefore, the subdivision of finite element grid can reach the desired effect and satisfy the accuracy of finite element calculation.

\section{Results and Discussions}

A two-dimensional transient simulation model of five-phase PMBLDC motor and a three-phase PMBLDC motor from Crouzet were modeled in the Maxwell 2D module software, namely, Ansoft Maxwell. Both motors' rating is tabulated in Table 2.

4.1. Analysis of Electromagnetic Field. The distributions of magnetic line are made at the transient simulation time of $23 \mathrm{~ms}$ five-phase motor and three-phase motor. Similarly, the magnetic flux density for five-phase and three-phase motors is done at $21 \mathrm{~ms}$ and $25 \mathrm{~ms}$. The results are shown in Figures 5 and 6, respectively. From the figure, the red magnetic line of force is positive extreme, the blue magnetic line of force is negative extreme, and there are flux leakages in stator slots too. Figure 5 gives the distribution of magnetic lines in three- and five-phase PMBDLDC motor. It is seen that in a three phase motor the area occupied by the flux lines for a given angular position are more creating more stranded losses, but in case of five phase motor the area occupied by the flux lines for a given angular position is less, thereby generating low stranded losses. Moreover, the distribution of flux around the air gap periphery is nonuniform in a three-phase motor compared to five-phase PMBLDC motor. Figure 6 shows that the magnetic flux density is higher in the yoke part of the stator and exhibits deeper color which results from permanent magnets. Through analyzing the distribution of magnetic line, the specific distribution of internal complicated magnetic field in the motor and magnetic saturate situation of each part can be ascertained in this work so as to provide a better theoretical basis to optimize the structure of the motor.

4.2. Analysis of Dynamic Processes. The induced voltages of the no load and load of five-phase PMBLDC motor are carried on simulation computation, and the simulation results were compared, as shown in Figure 7 (with load) and Figure 9 (with no load). Figure 7 shows that the load voltage distribution of stator winding induced EMF is nonsinusoidal 


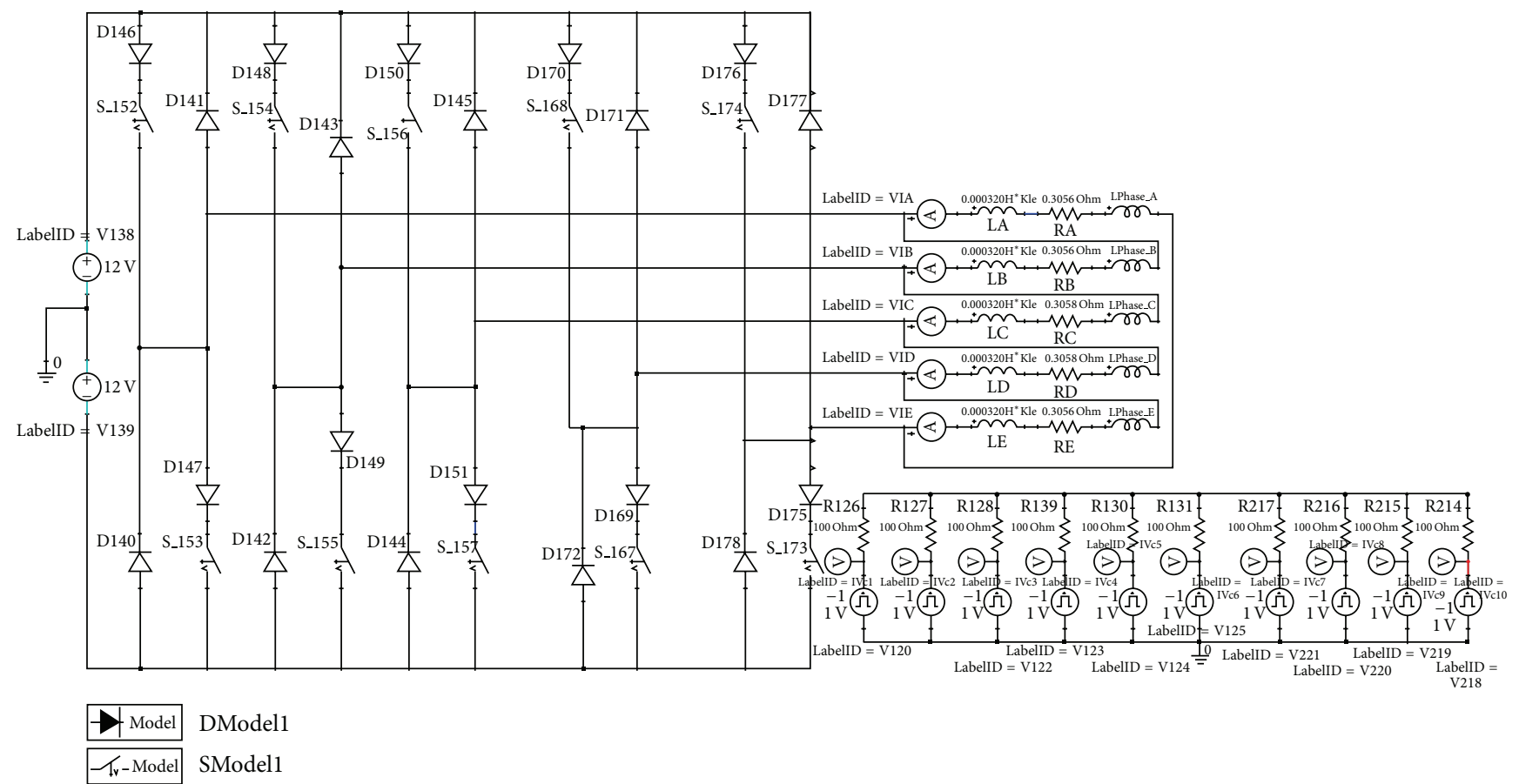

Figure 3: Control circuit system.

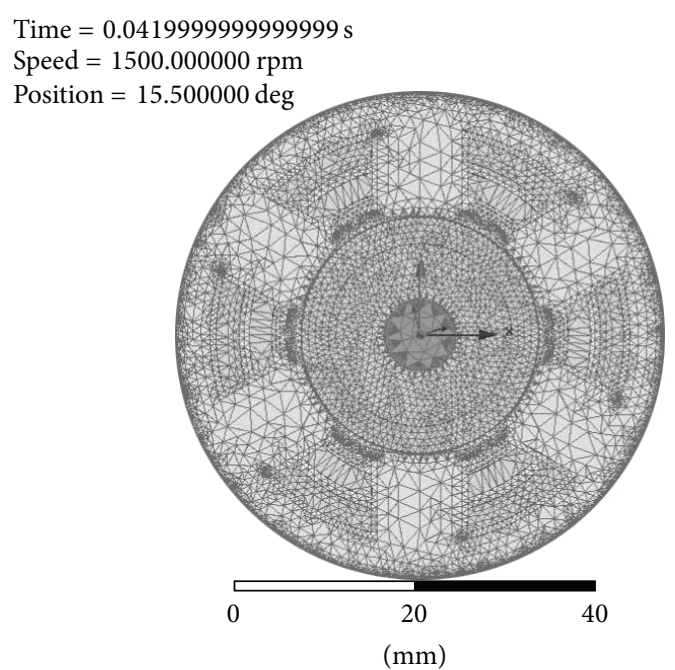

(a)

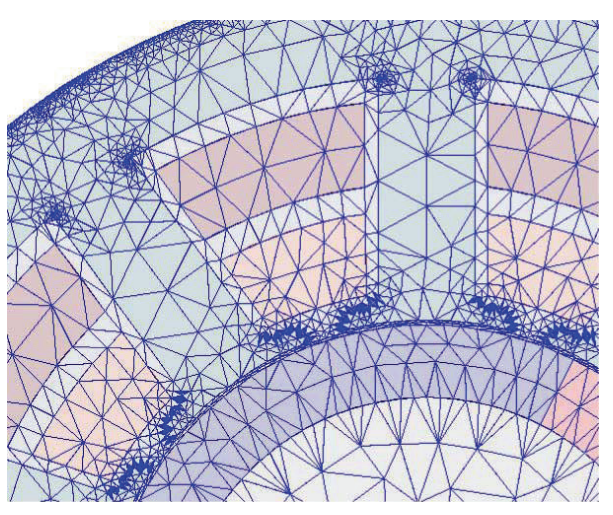

(b)

Figure 4: Grid subdivision model (time $=41.9 \mathrm{~ms}, 15.5$ deg displacement). (a) Overall subdivision model. (b) Partial enlargement model.

and approximately less than no load voltage. It gives the dynamic behavior of induced voltage for a five-phase motor when loaded with $0.2 \mathrm{Nm}$ load torque at $1500 \mathrm{rpm}$. It is seen that the speed of the motor drops from $1500 \mathrm{rpm}$ to $628 \mathrm{rpm}$ within $33 \mathrm{~ms}$. The induced EMF also drops from $8.2 \mathrm{~V}$ to $6.1 \mathrm{~V}$ peak voltage for phase winding A.

4.3. Waveforms and Discussions. The waveforms for both the three-phase and five-phase motors running at $1500 \mathrm{rpm}$ are shown for no load conditions. Figure 8 shows the phase currents of the motors indicating that the current drawn by the five-phase motor is 1.2 times that of three-phase motor. Similarly, Figure 9 infers that the five-phase induced voltage is 1.4 times that of three-phase motor. Figure 10 shows that the five-phase flux linkage is 1.3 times that of the three-phase motor. The motoring torque of the two motors is shown in Figure 11. It is seen that the torque of the three-phase motor varies from 0.18 to $1.7 \mathrm{Nm}$ over one cycle producing an average torque of $0.94 \mathrm{Nm}$. In case of five-phase motor, 
TABLE 2: Three-phase and five-phase motors.

\begin{tabular}{lccc}
\hline \multirow{2}{*}{ Parameters } & Symbol & \multicolumn{2}{c}{ Type of motor } \\
& & 3-phase Crouzet PMBLDC motor & 5-phase developed PMBLDC motor \\
\hline Rated power & $P$ & $160 \mathrm{~W}$ & $210 \mathrm{~W}$ \\
Rated input voltage & $V_{\text {in }}$ & $24 \mathrm{~V}$ & $24 \mathrm{~V}$ \\
Rated armature current & $I_{a}$ & $8.8 \mathrm{Amps}$ & 10.8 \\
Rated speed & $N$ & $3500 \mathrm{rpm}$ & 1400 \\
Resistance (per phase) & $R_{a}$ & $0.12 \Omega$ & $0.305 \Omega$ \\
Armature inductance & $L_{a}$ & $0.6 \mathrm{mH}$ & $0.32 \mathrm{mH}$ \\
Magnetic flux linkage & $\Phi$ & $0.02 \mathrm{~Wb}$ & $0.02 \mathrm{~Wb}$ \\
Number of poles & $P$ & 4 & 4 \\
Rated torque & $T$ & $0.4365 \mathrm{Nm}$ & $1.5 \mathrm{Nm}$ \\
Winding configuration & & Delta & Delta \\
\hline
\end{tabular}

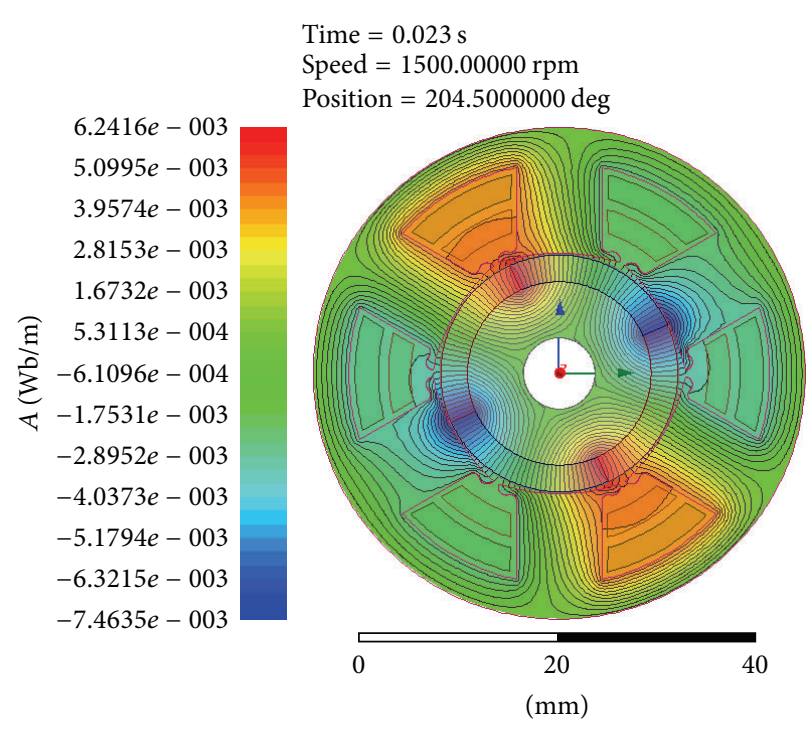

(a)

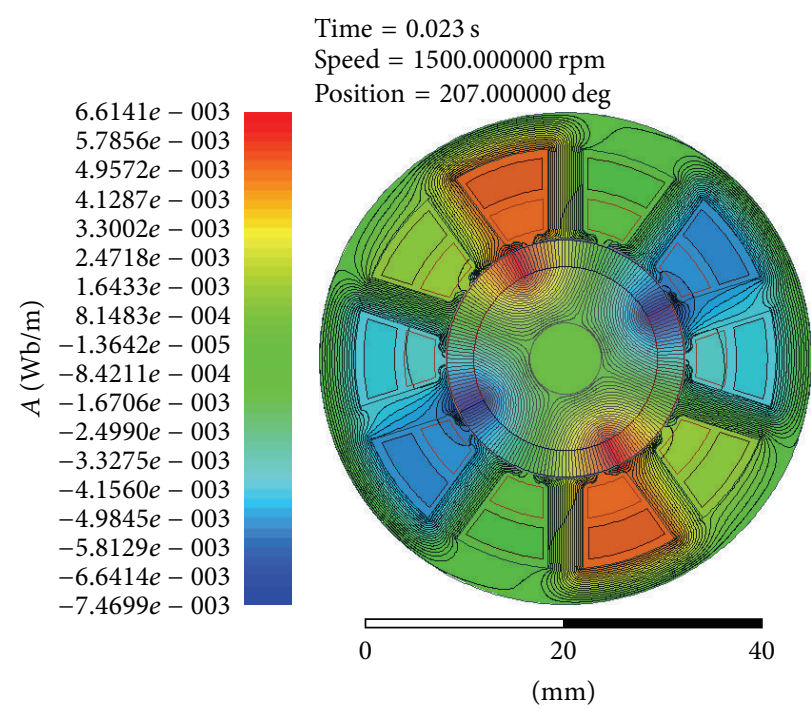

(b)

FIGURE 5: Distribution of magnetic lines in three- and five-phase motors.

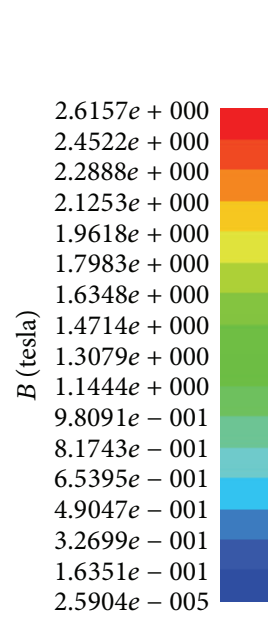

Time $=0.025 \mathrm{~s}$

Speed $=1500.000000 \mathrm{rpm}$

Position $=222.500000 \mathrm{deg}$

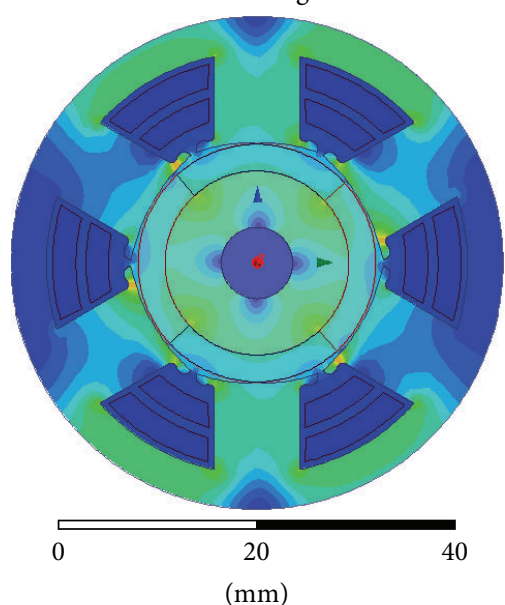

(a)

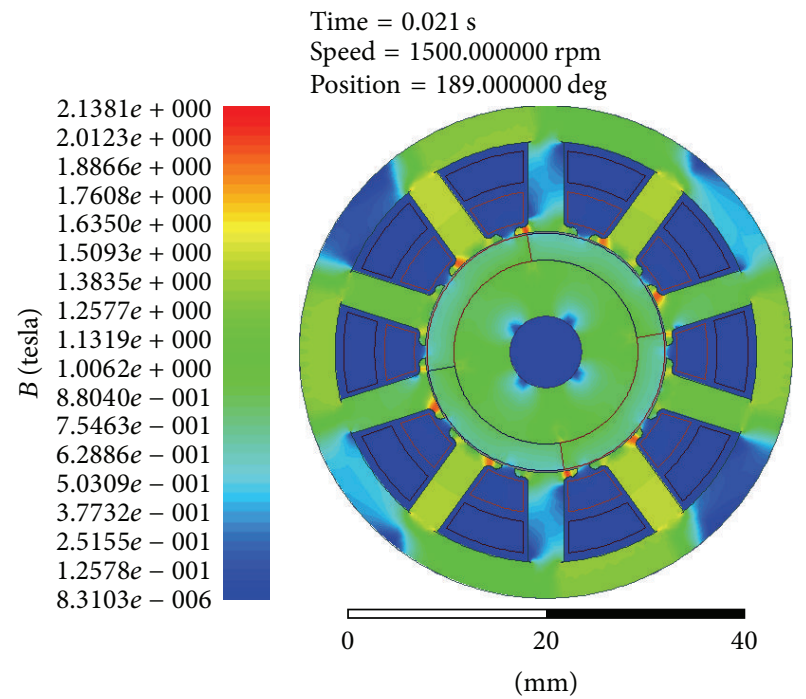

(b)

FIGURE 6: Magnetic flux density in three- and five-phase motors. 


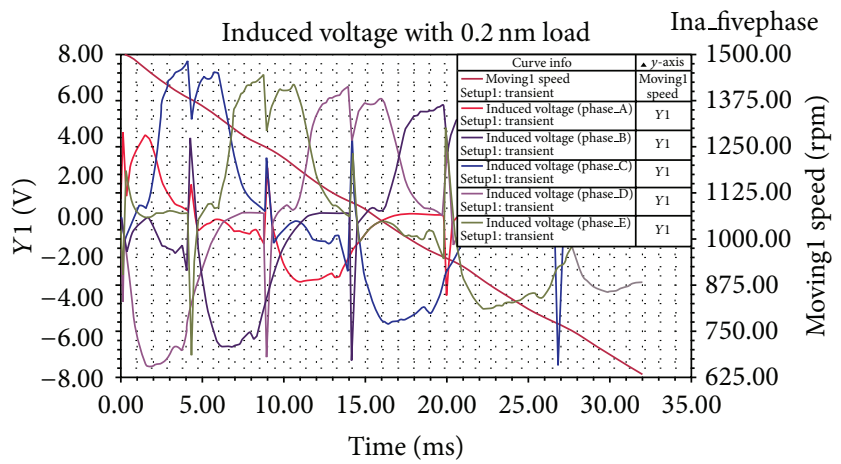

FIGURE 7: Five-phase induced voltage and speed (with a load torque of $0.2 \mathrm{Nm}$ ).
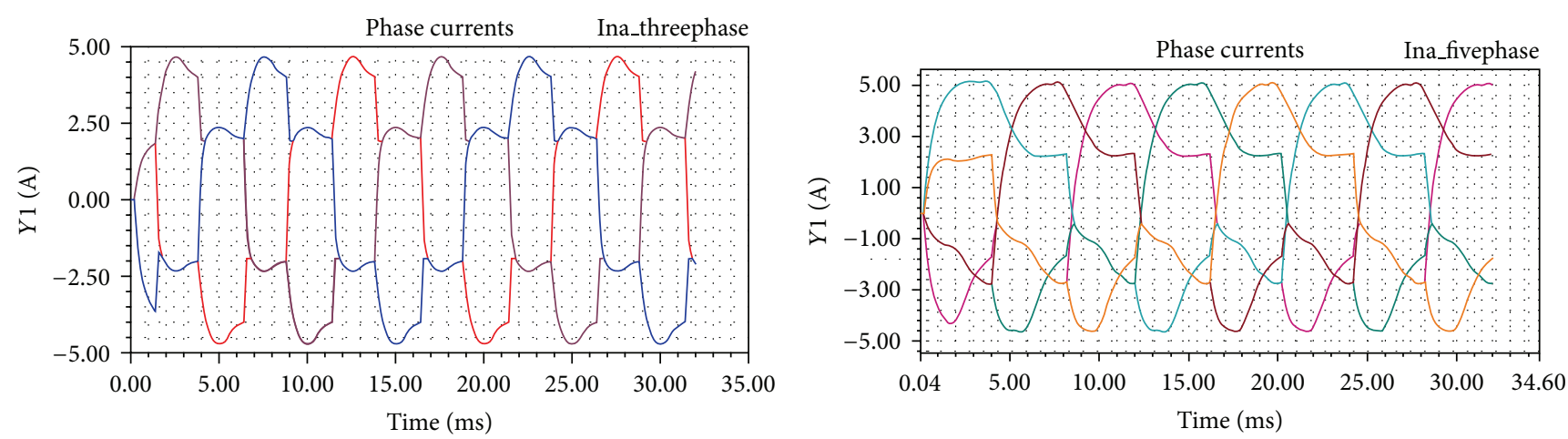

Curve info

_ Current (phase_A)

Setup1: transient

— Current (phase_B)

Setup1: transient

— Current (phase_C)

Setup1: transient

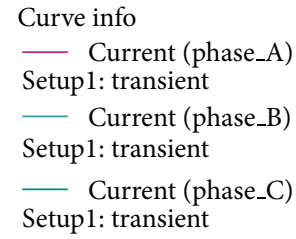
- Current (phase_D)
Setup1: transient
_ Current (phase_E)
Setup1: transient

(a)

(b)

FIGURE 8: Three-phase and five-phase currents.
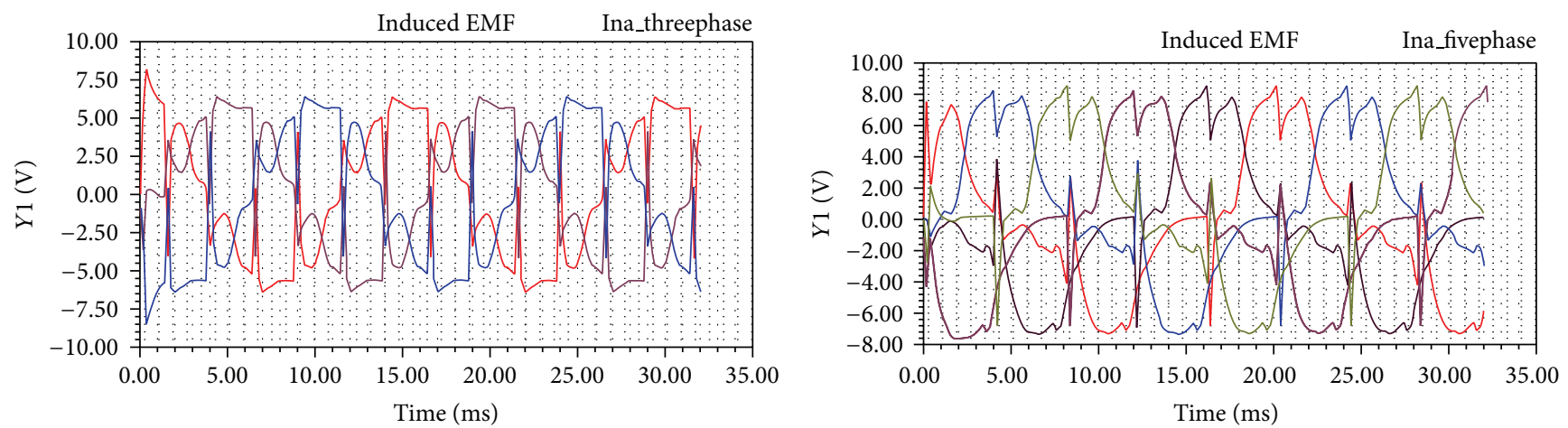

Curve info

_ Induced voltage (phase_A)

Setup1: transient

_ Induced voltage (phase_B)

Setup1: transient

Curve info

_ Induced voltage (phase_A)

Setup1: transient

- Induced voltage (phase_D)

— Induced voltage (phase_B)

Setup1: transient Setup1: transient

- Induced voltage (phase_C)

— Induced voltage (phase_E)

- Induced voltage (phase_C)

Setup1: transient

Setup1: transient Setup1: transient

(a)

FIGURE 9: Three-phase and five-phase induced voltages. 

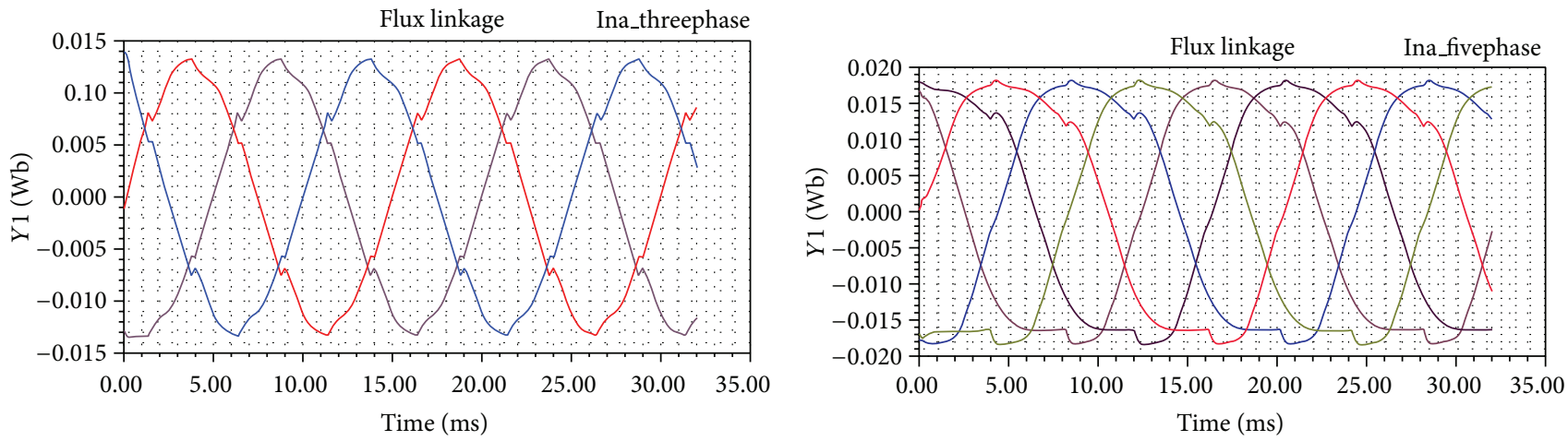

Curve info

_ Flux linkage (phase_A) Setup 1: transient

Curve info

- Flux linkage (phase_B)

Setup1: transient

- Flux linkage (phase_C)

Setup1: transient

(a)

Flux linkage (phase_A)
Setup1: transient
Setup1: transient
Setup1: transient

— Flux linkage (phase_D) Setup1: transient

_ Flux linkage (phase_E) Setup 1: transient

FIGURE 10: Three-phase and five-phase flux linkages.

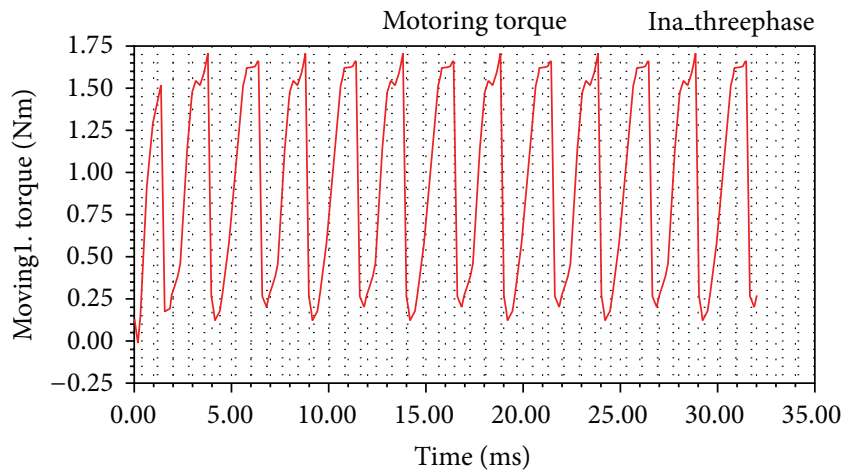

Curve info - Moving1. torque Setup1: transient

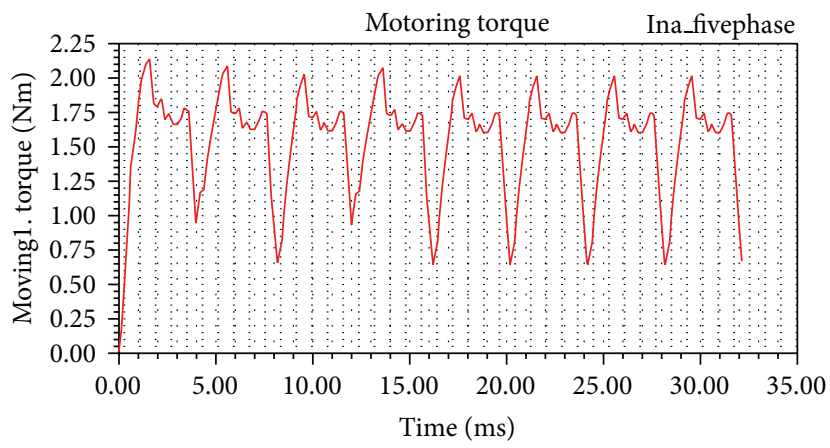

$\begin{array}{lc}\text { Curve info } & \text { Avg. } \\ \text { Setup1: transient } & 1.5554\end{array}$

(b)

FIGURE 11: Three-phase and five-phase motoring torques.

the torque varies from $0.92 \mathrm{Nm}$ to $2.2 \mathrm{Nm}$ over one cycle producing an average torque of $1.56 \mathrm{Nm}$. These results show that the torque produced in a five-phase motor running at $1500 \mathrm{rpm}$ is 1.6 times the torque of a three-phase motor having the same $D / L$. From the above torque values, it is concluded that the torque ripple of the five-phase motor is 50.29\% less than that of the three-phase motor as seen in Figure 13. Figure 12 indicates that the five-phase stranded loss is 2.19 times that of three-phase motor.

\section{Conclusion}

The software Maxwell 2D was adopted to establish the simulation model of five-phase brushless direct current motor by finite element analysis. The transient and dynamic performance of the motor are accurately accomplished. Simulation results show that the internal magnetic field distribution is reflected accurately and also provides a theoretical basis to make further optimal design. The main properties of the motors include electromagnetic torque, speed, winding induced voltage, and power loss, which can provide a reference to reduce torque ripple, improve the starting torque, and make further optimal design of the motor. It is also shown that the torque ripple in five-phase PMBLDC motor is low compared to its three-phase counterparts. It is concluded that the average torque produced in a five-phase motor running at $1500 \mathrm{rpm}$ is 1.6 times the torque of a three-phase motor having the same $D / L$, and the torque ripple of the five-phase motor is $50.29 \%$ less than that of the three-phase motor. Though 


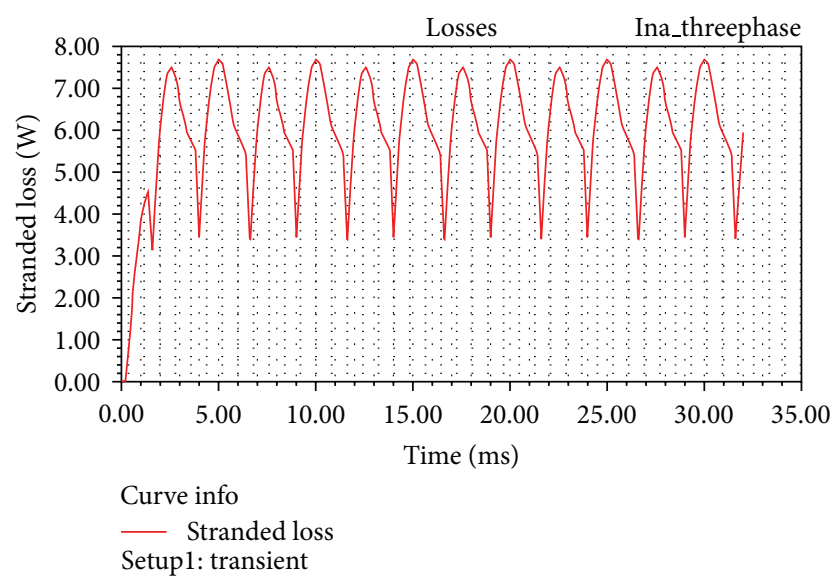

(a)

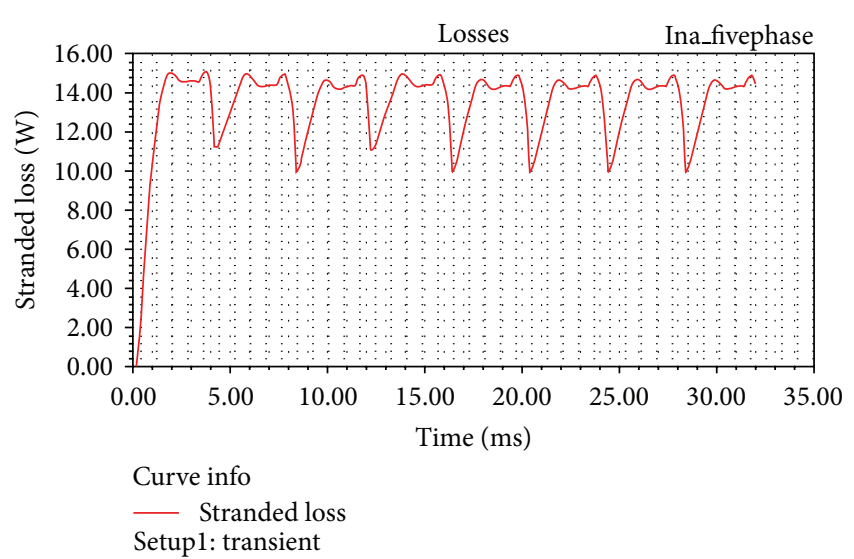

(b)

FIGURE 12: Three-phase and five-phase stranded losses.

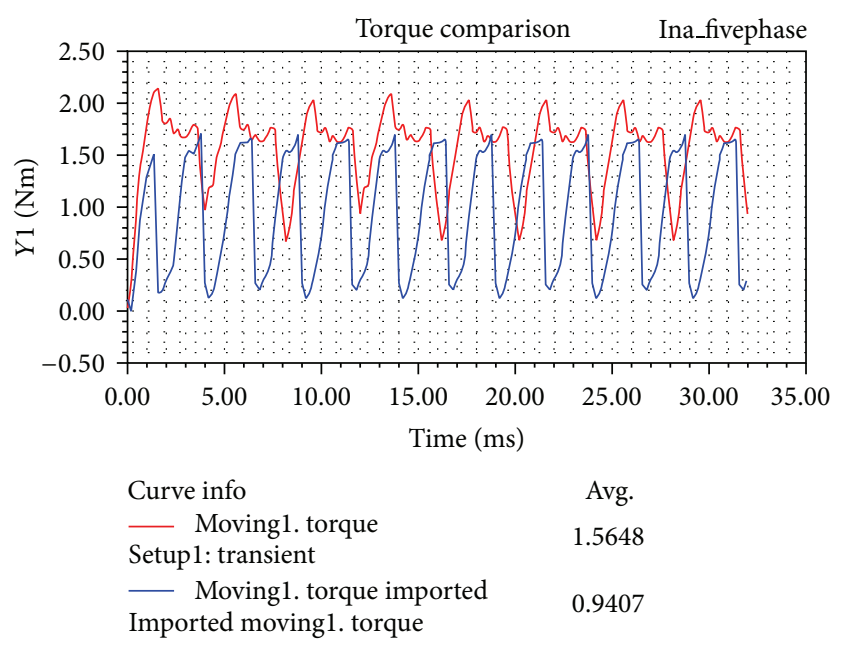

FIGURE 13: Three-phase and five-phase torque comparison.

the amount of torque ripple present in this analysis for threephase and five-phase motors is not desirable, this method of analysis will enhance the theoretical understanding on motor design and its impact on motor performance.

\section{Conflict of Interests}

The authors declare that there is no conflict of interests regarding the publication of this paper.

\section{References}

[1] A. Kusko and S. M. Peeran, "Definition of the brushless DC motor," in Proceedings of the IEEE Industry Application Society Annual Meeting (IAS '88), pp. 20-22, 1988.

[2] J. R. Hendershot and T. J. E. Miller, Design of Brushless Permanent-Magnet Motor, Oxford Science, 1994.

[3] T. Kenjo and S. Nagamori, Permanent Magnet and Brushless DC Motors, Tokyo Sogo Electronics, 1984.
[4] L. Rui-Fang, Y. Deng-Jun, and H. Min-Qiang, "Field circuit and movement coupled time stepping finite element analysis on permanent magnet brushless DC motors," Proceedings of the Chinese Society of Electrical Engineering, vol. 27, no. 12, pp. 5964, 2007.

[5] M. A. Inayathullaah and R. Anita, "Advanced simulation model of five phase PMBLDC motor drive for low power high torque applications," International Review on Modelling and Simulations, vol. 5, no. 5, pp. 2136-2145, 2012.

[6] B. Zhao and L. Zhang Hong, Ansoft 12 in Project Electromagnetic Field Application, China Water Power Publication, Beijing, China, 2010.

[7] Z. B. Yang, Z. Y. Huang, and X. H. Zhang, "Simulation and analysis starting performance of switched reluctance motor based on ansoft/maxwell 2D," Micromotor, vol. 42, no. 8, pp. 1922, 2009.

[8] W. E. Zhang, L. Wei, and S. Jia-feng, "Calculation and simulation of the back EMF and cogging torque of brushless DC motor," Journal of Harbin Institute of Technology, vol. 38, no. 2, pp. 297-300, 2006.

[9] J. Wang, F. Wang, and X. Kong, "Design and analysis of electromagnetic properties for high speed PM generator," Proceedings of the Chinese Society of Electrical Engineering, vol. 28, no. 20, pp. 105-110, 2008. 

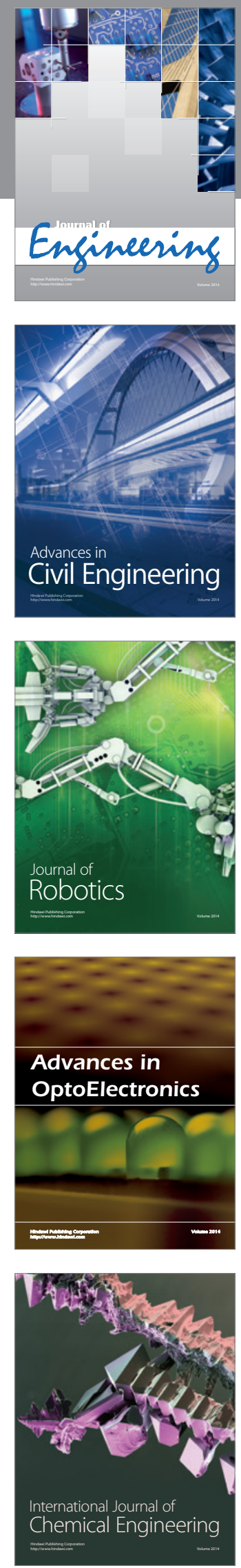

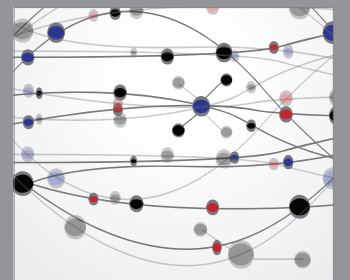

The Scientific World Journal
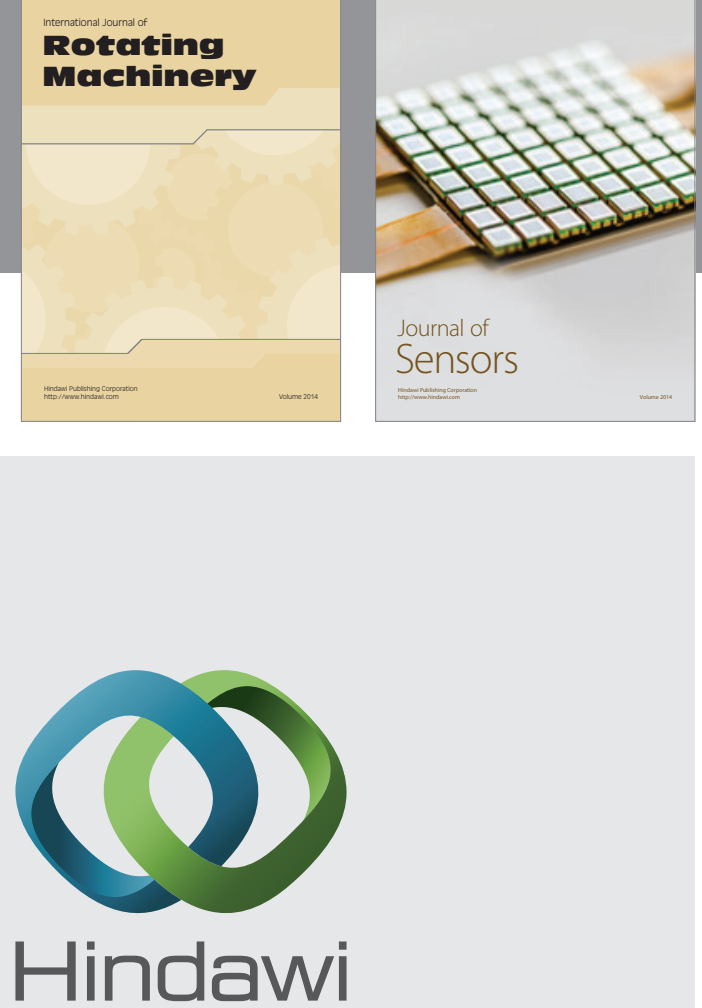

Submit your manuscripts at http://www.hindawi.com
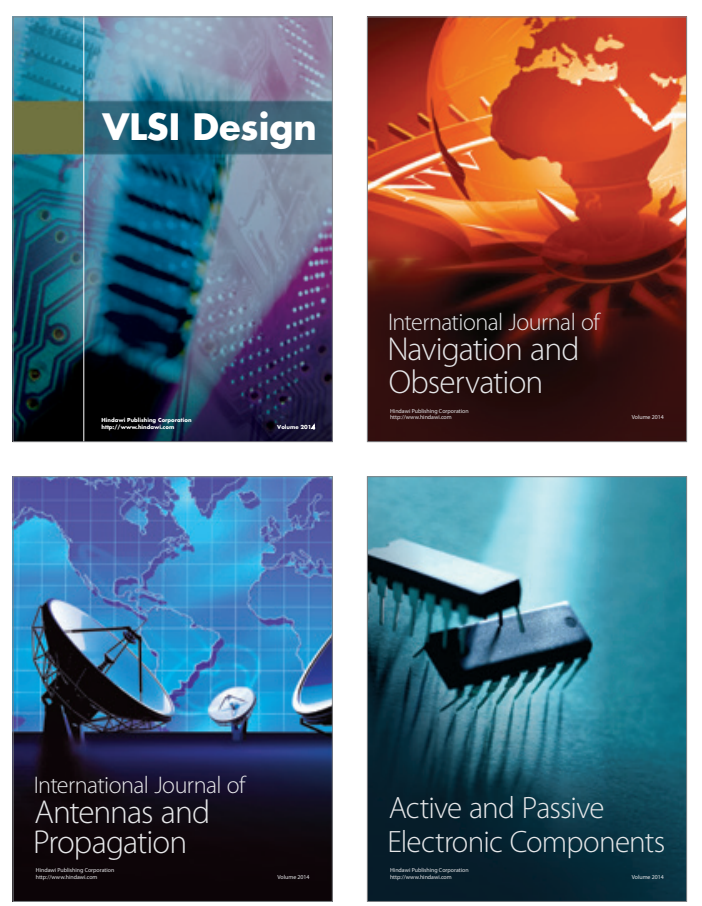
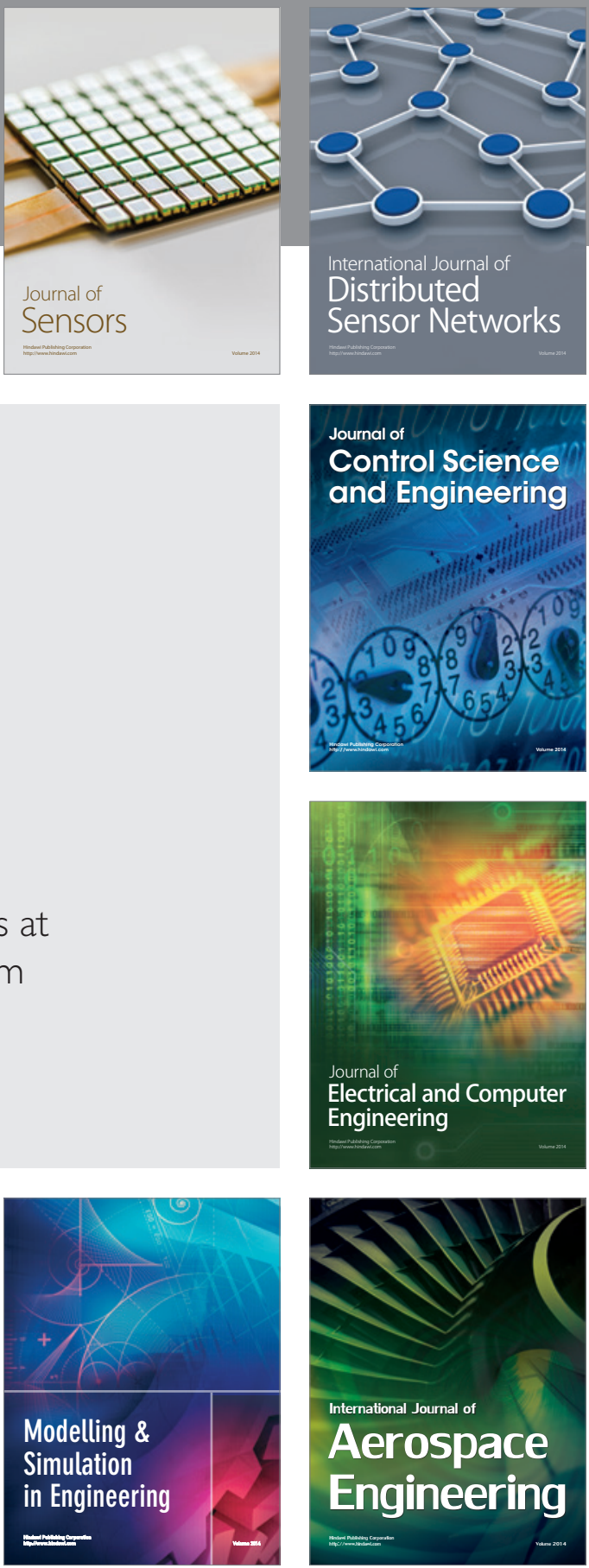

Journal of

Control Science

and Engineering
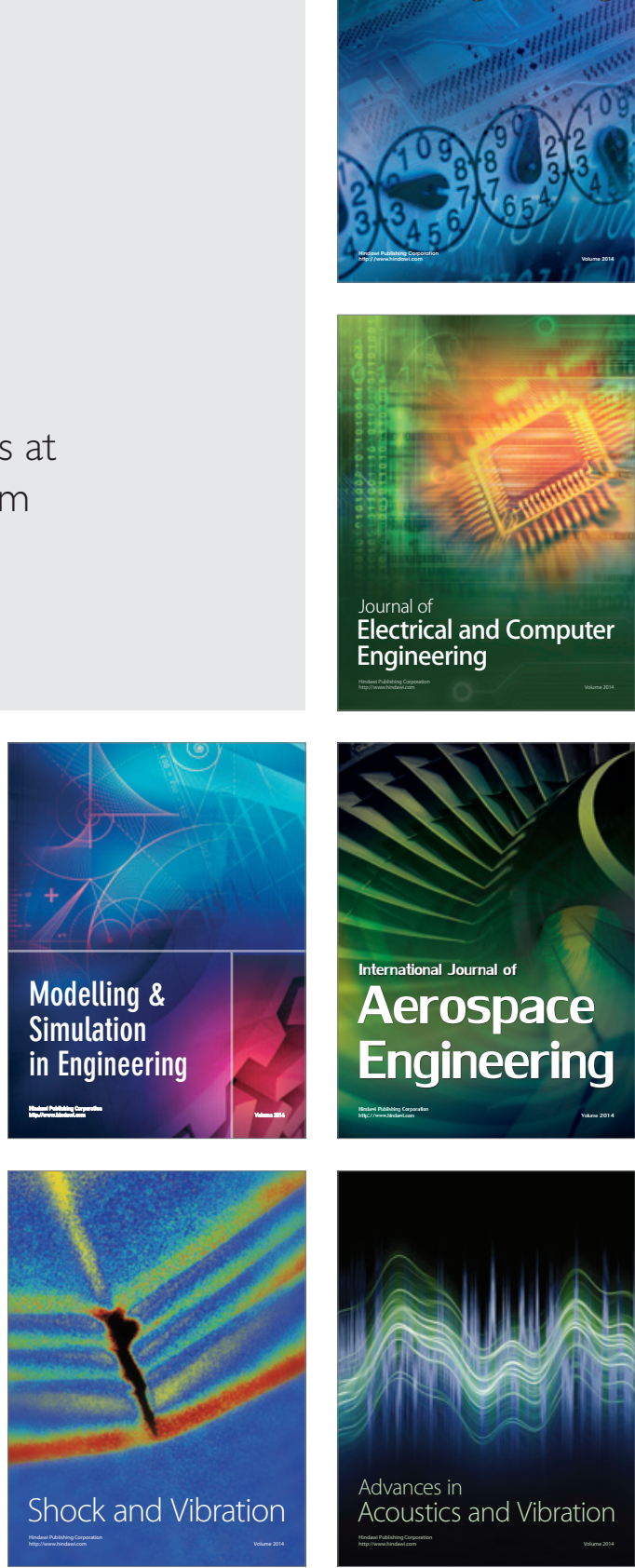